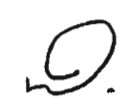

\title{
350.8
}

\section{Ingresso de indivíduos de capacidade limitada no Serviço Público: - Subsídio para solução do problema*.}

\section{Nair Lemos Gonçalves}

Livre Docente e 1.a Assistente da Cadeira de Legislação Social da Faculdade de Direito da Universidade de São Paulo. Vice-diretora do Seminário de Legislação Social e do Instituto de Direito Comparado do Trabalho e da Segurança Social, anexos à mesma Cadeira. Membro da Sociedade Internacional de Direito do Trabalho e da Segurança Social (Genebra) e do Instituto de Direito Social (S. Paulo).

Esta comunicação tem por fim apresentar meio jurídico de conciliar o interêsse do aproveitamento de pessoal de capacidade limitada com as exigências legais das provas de sanidade para provimento de cargos e funções no serviço público.

2. Segundo a legislação em vigor, e especialmente o art. 186 da Constituição Federal, "a primeira investidura em cargo de carreira e outros que a lei determinar efetuarse-á mediante concurso, precedendo inspeção de saúde."

Satisfeitos os requisitos de preenchimento do cargo, dois são os principais direitos atribuídos, também pela Constituição Federal, aos funcionários ef etivos, no que diz respeito à garantia de permanência no serviço público:

* Contribuição ao I Congresso Brasileiro de Medicina Física e Reabilitação, realizado em São Paulo, Brasil, de 13 a 16 de dezembro de 1961.

Vide também, nesta Revista, aula proferida pela A. sôbre As condições de sanidade nas relações entre o funcionário e o Estado. 
a) estabilidade, adquirida após dois anos de exercício, nas hipóteses de ingresso mediante concurso ou depois de cinco anos nos demais casos: e

b) vitaliciedade, direito restrito aos magistrados, Ministros do Tribunal de Contas, titulares de ofício de justiça e professôres catedráticos.

O funcionário estável só perde o cargo quando êste se extingue ou na hipótese de demissão precedida de processo administrativo, no qual se assegura ampla defesa, e o vitalício sòmente por sentença judiciária.

3. Como é sabido, cogita-se há muito do problema do aproveitamento de pessoal de capacidade reduzida. Já em 1943, por proposta do Departamento Administrativo do Serviço Público, expediu-se o Decreto-lei federal 5.895, que autorizou aquêle Departamento a baixar normas reguladoras dêsse aproveitamento. Em nosso Estado medida semelhante consta da Lei n. $^{\circ} 3.794$. de 5 de fevereiro de 1957, regulamentada pelo Decreto 29.958, de 22 de outubro do mesmo ano.

4. Tivemos oportunidade de integrar a Comissão presidida pela Prof a Eugênia Moraes de ANdrade, então Diretora da Divisão de Seleção e Aperfeiçoamento do Departamento Estadual de Administração de S. Paulo, que elaborou o projeto transformado no decreto 29.958, e verificamos ser convicção geral a de que nem todos os casos de deficiência física permitem pronunciamento imediato sôbre a suficiência da capacidade do candidato para exercício de determinada função ou cargo, tornando-se indispensável o "following up", posterior ao início das atividades do minorado, o qual o decreto 29.958 denominou de "periodo de adaptação"

5. Aparece, portanto, aqui a grande dificuldade da investidura em cargos em caráter efetivo e especialmente naqueles como o de professor catedrático do ensino secundário oficial e do superior oficial ou livre, cujos ocupantes serão vitalícios, por fôrça do inciso VI do art. 168 da Constituição Federal. Esta uma das razões principais de haver 
no decreto 29.958 disposição expressa excluindo de suas normas as nomeações em caráter efetivo.

6. Nos meios especializados. têm-se aventado várias medidas para solução do problema. Ainda recentemente. estudos sôbre o ingresso de professôres cegos no ensino oficial, realizados na Chefia do Serviço de Ensino Secundário e Normal da Secretaria da Educação, de que participaram a auxiliar técnica daquele órgão. Sra. Constância Lepera de Paiva e a Sra. Teresinha Rossi. como representante da Fundação para o Livro do Cego do Brasil. concluíram pela necessidade de laudo médico inicialmente provisório que, após determinado prazo de exercício no cargo, seria substituído pelo definitivo.

7. Por outro lado, na execução do decreto 29.958 verificou-se que o órgão médico encarregado das inspeções de saúde nem sempre compreendia o real objetivo do aproveitamento dos minorados, negando aplicação do decreto a casos em que a pessoa não preenchia determinado limite de capacidade, por não possuir o sentido correspondente, embora tal deficiência não impedisse o exercício da função a desempenhar. Diga-se de passagem que esta atitude é compreensivel da parte de órgão incumbido de modo geral da seleção de futuros servidores públicos, porque atende ao propósito de assegurar índice de sanidade e capacidade cada vez maior no serviço público, não sendo sua preocupação dominante a da reabilitação. Aquela dificuldade não apareceria, certamente, se a competência para decisão de tais casos fôsse atribuída a serviço especializado de reabilitação.

8. O problema apontado surgiu também nas reuniões, a que assisti como assessôra do Prof. Cesarino Jr., do Grupo de Trabalho constituido no Ministério da Educação, integrado pelos Srs. Ministro Francisco da Rocha Lagoa, Desembargador Bulhões de Carvalho, Prof. A. F. Cesarino Jr., Dr. Roberto Taliberti. Prof. Carlos Pasquale, Dr. álvaro Alvares de Silva Campos e Prof.a Dorina Gouvêa Nowill, como coordenadora. 
9. O estudo do assunto convenceu-nos de que entre as disposições constitucionais vigentes sôbre a prova de sanidade e capacidade física exigida para ingresso nos cargos públicos e o aproveitamento de pessoas com capacidade limitada existe apenas contradição aparente, que fàcilmente se dissiparia com uma lei que interpretasse de maneira mais compreensiva as citadas disposições.

10. As medidas, constantes da minuta anexa de anteprojeto de lei federal passível de ser adotada também nos Estados, poderão, a nosso ver, solucionar o assunto de forma satisfatória, fazendo desaparecer essa contradição aparente:

a) Reconhecimento da posse e do exercicio em caráter condicional. Enquanto não preenchida a condição suspensiva contida na prova de sanidade e capacidade física para a função ou cargo, não se verificará investidura definitiva, regulando-se a vida funcional do servidor, no que couber, pelas disposições próprias do funcionário interino e não se lhe assegurando qualquer direito de permanência no serviço público.

b) Atribuição ao serviço de reabilitação de competência para decidir, em grau de recurso, sôbre a capacidade ou não para determinados cargos ou funções de pessoal de capacidade limitada.

c) Divisão, quando necessário, da prova de sanidade e capacidade física em duas partes:

I - exames iniciais de que resultará laudo provisório; e

II - periodo de observação (expressão preferida a "período de adaptação", para evitar confusão com fases da reabilitação), durante o qual o servidor ficará sob fiscalização e contrôle do serviço de reabilitação.

d) Esclarecimento de que as causas de invalidez que justificam aposentadoria devem ser estados patológicos verificados após o ingresso no serviço público, proibida conseqüentemente a expedição, para êsse efeito, de laudo médico 
fundamentado em limitação de capacidade de natureza e grau idênticos aos indicados no que autorizou ingresso.

11. Notar-se-á desde logo que a minuta não restringe a possibilidade de recurso a pessoas anteriormente reconhecidas como "reabilitadas" por centros de reabilitação idôneos, porque esta restrição seria no momento inadequada, por não existirem ainda tais centros em número suficiente e não acarretar, a solução proposta, qualquer prejuizo quer para os "reabilitados", quer para o serviço de reabilitação.

Com efeito, se se tratar de pessoa reabilitada para a função ou cargo em questão, o serviço de reabilitação terá apenas de confirmar o fato, expedindo, para os efeitos da lei, laudo favorável à investidura. Se, ao contrário, o candidato não houver sido submetido a processo regular de reabilitação, o serviço de reabilitação expedirá, conforme os resultados dos exames que realizar, laudo definitivo negativo ou positivo, ou laudo provisório. Tais exames constituirão, além disso, oportunidade para identificação de casos passíveis da reabilitação, de que se incumbe o serviço de reabilitação que, ao expedir laudo negativo para a função ou cargo objeto do recurso, poderá também encarregarse de preparar o minorado para aproveitamento em outras posições futuras.

12. A competência do serviço de reabilitação apenas em grau de recurso tem por fim realizar certa triagem dos casos.

13. O propósito desta comunicação é o de apontar aos especialistas em reabilitação, notadamente aos médicos, um novo conceito de inspeção de saúde que, através do período de observação, como condição suspensiva, possibilitaria a aplicação dos preceitos constitucionais de estabilidade e vitaliciedade sòmente depois que o servidor provou ser suficientemente capaz para o exercício do cargo.

O prazo do período de observação, bem como a organização do serviço de reabilitação, constituem certamente questões de técnica de reabilitação que só pelos especialistas 
nessa matéria poderão ser convenientemente tratadas. A minuta representa apenas o meio jurídico julgado adequado para afastar as dificuldades de ingresso, no serviço público. de pessoas com limitação de capacidade.

Minuta de anteprojeto de lei federal.

Artigo $10^{\circ}$ - As condições de capacidade para o exercício das profissões técnico-científicas e liberais, no que se refere à sanidade e capacidade física, serão fixadas de conformidade com as exigências dos cargos, funções ou atividades a serem exercidas.

$\S 10^{\circ}$ - Quando o cargo, a função ou atividade tiver denominação de caráter amplo, compreendendo mais de IIm conjunto perfeitamente delimitado de atribuições, conslituindo cada conjunto uma ocupação distinta, as condições de sanidade e capacidade física deverão corresponder às exigências próprias de cada ocupação.

$\S 2 .^{\circ}-\mathrm{O}$ disposto neste artigo se aplica ao preenchimento de funções e cargos públicos.

Artigo $2 .^{\circ}$ - Consideram-se indivíduos de capacidade física limitada aquêles que não puderem preencher ou não atingirem quaisquer limites mínimos de sanidade e capacidade física para o exercício normal de cargos ou funções.

$\S 10^{\circ}$ - A limitação da capacidade física não constituirá impedimento à investidura em funções ou cargos públicos. quando a deficiência verificada não impedir o exercício do cargo ou função, ou de determinadas tarefas próprias de tais cargos ou funções, desde que tais tarefas constituam ocupação distinta, conforme estabelece o $\S 1 .^{\circ}$ do artigo $1 .^{\circ}$ desta lei.

$\S 2 .^{\circ}$ - Cabe ao serviço de reabilitação profissional competente decidir sôbre se a deficiência de que trata êste artigo não impede o exercício do cargo, função ou ocupação.

Artigo $3 .^{\circ}$ - Expedido, pelo órgão competente para realizar inspeções de saúde para ingresso no serviço público, 
laudo médico negativo baseado em limitação de capacidade física, poderá o candidato, no prazo de 5 (cinco) dias, a contar da publicação do resultado, recorrer dessa decisão ao serviço de reabilitação profissional.

$\S 1 .^{\circ}$ - No prazo de 15 (quinze) dias a contar do recebimento do recurso, o serviço de reabilitação profissional expedirá laudo devidamente fundamentado, com especificação das condições negativas (contra-indicações) e das positivas (indicações) do candidato, concluindo contràriamente ou não ao ingresso no cargo ou função, laudo êste que, nesta última hipótese, substituirá, para todos os efeitos legais, o anterior.

$\S 2 .^{\circ}-$ Nos casos em que o serviço de reabilitação profissional não possa expedir laudo definitivo contrário ou favorável à investidura do candidato ou porque a limitação verificada em sua capacidade física não apresente caráter definitivo, havendo possibilidade de agravação dela, ou porque o candidato apresenta elemento que leva a prever a possibilidade de alteração do seu estado de saúde, ou ainda porque julgue indispensável verificar a eficiência e ajustamento do servidor ao ambiente de trabalho, a inspeção de saúde dividir-se-á em duas partes:

a) exames iniciais, após os quais será expedido laudo provisório, que autorizará a investidura condicional no cargo ou na função; e

b) período de observação, durante o qual o servidor, investido em caráter condicional no cargo ou na função, ficará sob fiscalização e contrôle do serviço de reabilitação profissional.

$\S 30^{\circ}-$ À vista do laudo provisório a que se refere a alínea "a" do parágrafo anterior, a autoridade competente dará ao candidato posse e exercício em caráter condicional, o que deverá ser expressamente anotado no têrmo de posse e no título de nomeação ou no título de admissão, conforme o caso.

$\S 4 .^{\circ}$ - Nos concursos ou provas em que a inscrição do candidato ao cargo ou função dependa de inspeção de saúde, 
- laudo do serviço de reabilitação profissional, expedido nos têrmos desta lei, autorizará a inscrição do candidato em caráter condicional ou não, conforme se trate de laudo positivo, provisório ou não.

$\S 5 .^{\circ}$ - Os prazos fixados para posse e exercício serão considerados automàticamente prorrogados pelo tempo necessário à realização de exames e expedição do laudo médico pelo serviço de reabilitação profissional.

Artigo $4 .^{\circ}$ - Se o laudo do serviço de reabilitação fizer restrição a atribuições a serem desempenhadas ou especificar condições de trabalho, qualquer alteração das atividades do servidor dependerá sempre de parecer favorável do serviço de reabilitação profissional.

Artigo $5 .^{\circ}$ - 0 periodo de observação de que trata a alínea "b" do $\S 2 .^{\circ}$ do artigo $3 .^{\circ}$ será contado em dias corridos e terá o prazo máximo de:

a) 2 (dois) anos, quando se tratar de nomeação que sujeite o funcionário a estágio probatório; $\mathrm{e}$

b) 4 (quatro) anos quando não haja estágio probatório e nas hipóteses de admissão de pessoal variável do serviço público.

$\S 1 .^{\circ}$ - Durante o período de observação aplicar-se-ão, no que couber, à vida funcional do servidor as disposições próprias do funcionário interino, não lhe sendo assegurado qualquer direito que se refira a garantia de permanência no serviço pủblico.

$\S 2 .^{\circ}$ - A partir da data do laudo do serviço de reabilitação profissional que, declarando findo o periodo de observação, conclua pela confirmação da investidura no cargo ou na função, a posse e o exercício do servidor perderão o caráter condicional, passando a aplicar-se a êle integralmente o regime jurídico em vigor para os funcionários, extranumerário ou pessoal variável em geral, conforme a categoria a que pertencer ${ }^{1}$.

1. As disposições dêste artigo deverão ser revistas e adaptadas, porque a Lei n. ${ }^{\circ} 2.735$, de 18-2-56, reduziu o prazo de estágio probatório no serviço público federal. 
Artigo $6 .^{\circ}-$ A contagem do prazo de estágio probatório terá início na data do laudo a que se refere o $\S 2 .^{\circ}$ do artigo $5 .^{\circ}$.

Parágrafo único - As licenças para tratamento de saúde obtidas durante o estágio probatório, por motivo relacionado direta ou indiretamente com a deficiência de capacidade indicada no laudo que permitiu ingresso no cargo ou na função, terão valor preponderante na apuração dos requisitos a serem verificados através do estágio probatório, podendo ser consideradas, a critério do serviço de reabilitação profissional, como a própria negação da assiduidade, servindo de fundamento suficiente para exoneração do funcionário.

Artigo $7^{\circ}$ - Verificando em qualquer tempo, durante o periodo de observação, que as condições de sanidade do servidor não mais lhe permitem exercer o cargo ou a função com eficiência, inclusive em virtude de repetidas licenças, o serviço de reabilitação profissional encaminhará à autoridade competente laudo definitivo contrário à investidura. à vista do qual serão considerados automàticamente cancelados a posse e o exercicio no cargo ou na função e expedido ato declarando sem efeito, para todos os fins de direito, a nomeação ou admissão, por não ter o candidato satisfeito o requisito relativo à sanidade e capacidade física.

Parágrafo único - Em qualquer caso, o laudo definilivo a que se refere êste artigo deverá ser expedido obrigatòriamente até 4 (quatro) meses antes do término do período de observação.

Artigo $8 .^{\circ}-\mathrm{O}$ não comparecimento, sem causa justificada, do servidor convocado para exames pelo serviço de reabilitação profissional, durante o periodo de observação, constituirá insubordinação grave que autorizará a expedição imediata de laudo definitivo contrário à confirmação da investidura, com os mesmos efeitos indicados no artigo $7 .^{\circ}$.

Artigo $90^{\circ}$ - Das decisões do serviço de reabilitação profissional, nos têrmos desta lei, não cabe recurso. 
Artigo $100^{\circ}-\mathrm{A}$ autoridade competente deverá comunicar imediatamente, por escrito, ao serviço de reabilitação profissional a data do exercício condicional de servidor que abresentar laudo provisório, anotando no respectivo título de nomeação ou admissão a data dessa comunicação.

Artigo $110^{\circ}$ - As causas de invalidez que justificam a aposentadoria de servidor, inclusive a moléstia ou doença grave contagiosa ou incurável, a que se refere o $\S 3 .^{\circ}$ do artigo 191 da Constituição Federal, devem ser obrigatòriamente estados patológicos verificados após o ingresso no serviço público.

Parágrafo único - Aos servidores que ingressaram no cargo ou na função valendo-se de laudo expedido pelo serviço de reabilitação profissional nos têrmos desta lei, em caso algum poderá o órgão competente expedir laudo de aposentadoria, em virtude de limitação de capacidade física de natureza e grau idênticos aos indicados no laudo de ingresso.

Artigo $12 .^{\circ}$ - O regulamento disporá sôbre o serviço de reabilitação profissional competente para desempenhar as atribuições de que trata esta lei.

Artigo $13 .^{\circ}$ - A presente Lei entrará em vigor na data de sua publicação.

Artigo $14 .^{\circ}$ - Revogam-se as disposições em contrário. 